an inability which is shared by many, and by some to such an extent as to cause them to receive cum grano salis the statement itself, at least until it is accompanied with such data as will reasonably illustrate-first, why such common immunity should exist in two regions possessing such different climatic conditions, such different elevations, and such different topographical, geological, and regional formations as the places under consideration; and, secondly, what are the conditions, climatic or social, connected with either country which give its inhabitants freedom from a disease which, according to Professor Aitken, of Netley, is prevalent everywhere. ${ }^{1}$

Let us first direct our attention to Iceland, noting the difference between it and the steppes of Tartary, with a view of ascertaining whether the weight of evidence is in favour of freedom from phthisis, or the reverse.

Iceland. - This island is situated between $64^{\circ}$ and 65 north latitude; while the 20 th meridian of west longitude passes through it. It lies in the Arctic, or polar zone of disease, in a north-north-west direction off the coast of Scotland, from which it is distant about $5^{\circ}$. It is remarkable for its volcanoes and geysers, or hot springs. In extent of surface it is much larger than either Scotland or Ireland, and yet only maintains a scanty population of 60,000 souls; which, according to the rule applicable to all old countries, that the population of the country is in a direct ratio to the fertility of the soil, furnishes abundant evidence of the poverty and unhealthiness of the land, where leprosy, elephantiasis, and influenza prevail, and where--as Mr. Keith Johnson affirms-the vast majority of the inhabitants succumb before the age of fifty to asthma and catarrhal affections of the respiratory organs, brought on mainly by the extreme cold and the biting winds which prevail in the island for a great part of every year. The inhabitants are fish-eating to a considerable degree, and live in small, badly-ventilated huts, buried in many cases beneath the surface of the earth.

A great deal more might be added to this description, but I think enough has been said to show that the weight of evidence, reasoning from analogy, is against the immunity from consumption, and affording some proof, even, of the existence of that disease.

To what, may I ask, is to be attributed one-third of the death-rate of the British and other armies, in whatever climate they are found? The answer is-"consumption." And why? Because-according to Parkes, and all military surgeons who have written on the subject-of the confinement of the men in close barracks, assisted in some slight degree by unwholesome food, dram-drinking, and enforced celibacy, with the evils it entails-all of which, with the exception of the last, are found in Iceland, but to a much greater degree. Yet, are we to believe in a different result? If so, the effects of the climate must be marvellously good.

Again, according to Aitken and others, consumption is universal. And is it possible for us to avoid surmising the connexion between the asthma and catarrhal affections alluded to and phthisis? If so, we must fall back on the old theory of the disease, and put outside our consideration all we have learned of pneumonic phthisis, or tyrosis, which so often has its source in bronchitic or pneumonic catarrh, and is not unfrequently, at least on the hills of India, associated with asthma in its early stages.

The volcanic character of the country may, no doubt, possibly exercise a preventive or curative influence. It is said to do so at Solfatara, where the vapour from the crater of an extinct volcano had, even at Naples, a great reputation, but which diminished somewhat on a closer acquaintance. But granting this, it is the one favourable consideration : and, as its influence in such a large island must be local, I am forced to believe that the assumption of immunity is maintained by the difficulty of obtaining reliable information in such a remote and sparsely populated country.

Let us now leave Iceland and proceed to the steppes of Central Asia. Here we see a vast tableland at an elevation of from 3000 to 4000 feet above the level of the sea, situated just outside the torrid zone of disease, in the same latitude as Naples or Madrid $\left(40^{\circ} \mathrm{N}\right.$.), inhabited or rather occupied by a scattered population of nomadic tribes, dwelling in tents, or spending the greater part of their lives in the open air, and inured from childhood to a life of activity and exercise, exposed no doubt to annual extremes of temperature, but breathing continually a pure, rarefied, dry, and exhilarating atmosphere - in fact, surrounded by all the conditions which would, à priori, lead us to predict a considerable immunity, not only from phthisis, but many other forms of disease. Thus, so far as regards Tartary, the statement of Dr. Jagielski seems, if not absolutely, at least conditionally correct, furnishing us, however, with proofs, not against, but rather in favour of the value of mountain air ; for, with the one exception of stillness of the atmosphere, the conditions are not very materially removed from those which appertain to Davos.

In conclusion, it will be seen that on examination of the entourage, taken in its widest sense, if the two supposed happy lands have led us to opposite conclusions, on the one hand we have been compelled to dispel the fancied security of Iceland, while, on the other, we are forced to confirm what appears to be the undeniable claims of the swarthy nomads of the steppes.

I am, Sir, your obedient servant

D. H. CULLIMORE, F.R.C.S, \&c

Ex-Residency Surgeon at the Court of the King of Burmah. Devonshire-street, Portland-place, Aug. 19th, 1879.

\section{TREATMENT OF CHOLERA BY HYPODERMIC INJECTION OF MORPHIA.}

\section{To the Editor of THE LANCET.}

SIR,-I hope you will kindly give space in your valuable journal to the following interesting case of cholera, treated successfully by the hypodermic injection of morphia.

Mrs. Hfound suffering from all the symptoms of a severe attack of cholera. The usual medicines were all tried, but without any good, and the symptoms went on increasing in severity. Diarrhoea and vomiting became incessant, pulse fluttering and almost imperceptible at the wrist, with severe cramps and coldness of extremities, violent and unbearable pains in the abdomen, loss of voice, and partial coma. There was total incapability of retaining even a snzall quantity of food or medicine in the stomach. As all known medicines had failed in abating the symptoms, I resorted to the hypodermic injection of hydrochlorate of morphia (a quarter of a grain) into the right hypochondriac region. The effect of this was, to my mind, quite marvellous. The diarrhœea and vomiting ceased at once, the pains disappeared, the pulse was reestablished, and the patient rapidly recovered.

In two other similar cases of cholera treated with the same drug I have found it equally successful.

As a rule, in all cases of cholera I have been in the habit of administering pills composed of black pepper, camphor, and assafoetida, with the addition of opium, in the early stages of the disease. Out of eighty cases of cholera treated with these pills, only nine have died. These, too, would have probably been saved had they come under treatment at the proper stage.

Although these pills are not specific, they have proved very successful in my hands. The hypodermic injection of morphia deserves, in my opinion, further trials in this most formidable disease.

I remain, yours truly, Batukram S. MeHTA, Military Officer in Charge, Sayajirow Hospital, Baroda, India.

Sayajirow Hospital, Baroda, 17th July, 1879 .

\section{THE LATE MR. CLEMENT WILLIAMS. To the Editor of THE LANCET.}

SIR,-Will you permit me also, as a friendiof the late Mr. Clement Williams, of Mandalay, to express my sympathy with the excellent obituary notice of him which recently appeared in your columns. I entirely agree with your remarks concerning the loss sustained by the Government of our great Eastern Dependency through Mr. Williams being remanded to the mere routine of military duty. At Mandalay he was unquestionably the right man in the right place-a natural fitness of things which has not always ob. tained since Mr. Williams was removed from his official position in the Golden City. In your issue of the 9 th inst. (which came under my notice only yesterday) Mr. Cullimore speaks of his deceased friend in well-deserved terms of admiration; but he is in error when he asserts that Mr. Wil. 